\title{
A BVAR Analysis on Channels of Monetary Policy Transmission in Brazil
}

\author{
Francisco J. S. Rocha ${ }^{1}$, Marcos R. V. Magalhães ${ }^{1,2}$ \& Átila Amaral Brilhante ${ }^{3}$ \\ ${ }^{1}$ Department of Applied Economics, Federal University of Ceará, Brazil \\ ${ }^{2}$ CAEN - Graduate Studies in Economics, Federal University of Ceará, Brazil \\ ${ }^{3}$ ICA - Department of Philosophy, Federal University of Ceará, Brazil \\ Correspondence: Marcos R. V. Magalhães, CAEN - Graduate Studies in Economics, Avenida da Universidade, \\ 2762, CAEN building, 1st and 2nd floors, Benfica, CEP: 60.020-181, Fortaleza/CE, Brazil. Tel: (85)-3366-7751.
}

Received: December 31, 2021

Accepted: January 22, 2022

Online Published: January 26, 2022

doi:10.5539/ijef.v14n3p19

URL: https://doi.org/10.5539/ijef.v14n3p19

\begin{abstract}
This article measures the responses of GDP and inflation to a positive shock of the variables that make up the channels of transmission of monetary policy. The results of impulse-response functions of the estimated Bayesian VAR (BVAR) were: an increase in the short-term interest rate (SELIC) leads to a long-term interest rate increasing and consequently a reduction in GDP. Free credit does not have a significant impact on Brazilian GDP, given the low free credit/GDP ratio (Bogdanski et al., 2000). A shock in inflation expectations result in a decreasing trajectory of GDP, a fact consistent with the Fisher effect (Mishkin, 2009); and a shock at SELIC reduces inflation in the first two months, there is no "price puzzle". A credit shock does not cause significant pressures on inflation. The Inflation does not show a well-defined time path after a shock in asset prices. The decomposition of the variance of the forecast error, in turn, showed that: GDP, in the short term, has its forecast errors explained by its own shocks, $70 \%$ on average. However, in the medium term, their forecast errors are explained by their own shocks, around $35 \%$, by inflation shocks, $34 \%$, and by interest rate shocks, $20 \%$. The other transmission channels do not have, in the short and medium terms, significant influence on GDP forecast errors, except the asset prices; and inflation forecast errors are explained, in the short term, mainly by their own shocks, $85 \%$ on average. In the medium term, inflation forecast errors are explained $68 \%$ by inflation itself, $6 \%$ by GDP and the others transmission channels participate individually, with approximately $6 \%$. These results are robust when controlled for commodity prices.
\end{abstract}

Keywords: bayesian VAR, transmission channels of monetary policy, inflation

JEL: C11, C15, E52.

\section{Introduction}

In the current literature on monetary policy both Dynamic Stochastic General Equilibrium (DSGE) and Bayesian Vector Autoregressions (BVAR) models have helped improve the process that guides the issue of monetary policy implementation. There is a consensus by now that an adequate implementation of such policy is to be centered around the kind of information delivered to Central Bank, such as inflation evolution, testable hypotheses on the nominal rigidity underlying prices and wages, particular determinant to prices, evolution of output-credit gap, as well as the effects of monetary shock on certain variables.

Indeed, venerable researches have been elaborated as attempts to flesh out meaningful facts about the effect attached to the monetary policy transmission within nominal and real economic variables. In contrast to the received view, current techniques in line with Bayesian methods have drawn attention of many scholars. According to Cogley and Sargent (2005), Federal Reserve System (FED) adopts method like this one to evaluate the update of Phillips curve. In order to put forward its monetary policy plan, European Central Bank (ECB) organized a research group whose members also handle Bayesian techniques (Note 1). In Brazil they are not well-liked yet among economic policy theorists.

By means of impulse-response functions (IRFs) and variance decomposition (VD) of a BVAR model, we analyze the dynamic interface between traditional channels of monetary policy transmission (short-term interest rates, credit, asset prices, exchange rate and inflation prediction), inflation and the real gross domestic product 
(GDP). We initially start with Minnesota priors (Litterman, 1986). (Note 2) To notice the moving pattern of model variables, we equate the channels of monetary policy transmission with impulse variables, while inflation and GDP come to response variables.

BVAR analysis covers the sample period from January 2009 to December 2019, consisting of seven variables, five of them are impulse ones, namely: non-earmarked real credit balance, short-term interest rate (SELIC), inflation prediction prior a month to broad consumer price index (IPCA) setting up, São Paulo Stock Exchange index (Ibovespa), nominal exchange rate; and two response variables given by gross domestic product (GDP) and inflation (IPCA) (Note 3).

As it is designed, the payoff here is considerable. Firstly, by our lights, BVAR technique is unusual in the domain of macro monetary analysis concerning Brazilian economy. Secondly, the amount number of variables is substantial enough, it covers observations over an eleven-year period of monetary policy in which interest rate went from double-digit level to one (early $12.75 \%$ per year ended $4.5 \%$ ). Thirdly, it is a step further by introducing into the analysis the variable that captures the amount of credit in the economy issued from non-earmarked resources, as widely known that ulterior developments in the credit market have a far-reaching impact on economic activity as well.

The reason to resort BVAR model to analyze as the channel transmissions affect monetary policy regarding the output-inflation couple are the following: (i) it provides the solution to the question addressed by overparameterization usually observed in VAR models representative of classical econometrics. Unlike VAR oriented-techniques that are deprived of robustness (by and large asymptotic variances), BVAR model configurates as a rather robust one to value autoregressive vector, giving rise to a more reasonable analysis with respect predictions about variables along with impulse-response functions and variance decomposition (Doan et al. (1984); Bańbura et al. (2010); (ii) Bayesian VAR also solves the problem urged by the order of variable integrations reducing the sample size pertinence (Sims \& Uhlig, 1991).

There is a huge number of studies about Brazilian monetary policy outside the scope of Bayesian analysis. For example, Luporini (2008) analyzed the interest as a channel transmission as for a set of variables due the Brazilian economy in the 1990s (output, prices and exchange rate) using autoregressive vector system (VAR). The results he founded are robust and consistent with economic theory, namely: an increase in interest rates reduces economic activity, hence GDP growth is reduced while inflation follows a falling path. In similar way, Tomazzia and Meurer (2009) showed the negative reaction as for industrial sector to the exogenous monetary policy, differing only in the level of effect, having the consumer durable resource sectors the most positive answer.

As for the exchange rate to open economies, Squeff (2009) and Modenesi and Araújo (2013) indicated that changes in this variable entails persistent effects on Brazilian information, which then might be taken into account in monetary policy information. As such, these studies provide empirical evidence that exchange rate flows get a point influence on the price level.

With respect the monetary policy transmission mechanism via credit channel to Brazilian inflation targets, several empirical studies were outlined (Catão et al., 2008; Minella \& Souza-Sobrinho, 2013; Coelho et al., 2010; De Mello and Pisu, 2010; Auel \& de Mendonça, 2011). Auel and de Mendonça (2011) argue that interest rate shocks are not disseminated up the economy as well, but upon credit channels, which corroborates for the role played by such channel to the monetary policy.

Ultimately, as noted above, not many reference works occupy in investigating the transmission channels of monetary policy via BVAR models. Mallick and Sousa (2012) engaged to examine factual effects as for BRICS monetary policy (Brazil, Russia, India, China and South Africa). The authors demonstrate that contractionary monetary policy gets a strong and negative effect on output up to stabilize inflation in these countries in the short-term, while producing a strongly persistent negative effect on real prices within stock market. To sum up, it is noteworthy that there are several studies carried out for different countries that assess impacts of monetary policy shocks under the support of BVAR models: Czech Republic (Borys et al., 2009), Italy (Migliardo et al., 2010), New Zealand (Bloor \& Matheson, 2010), Romania (Spulbăr et al., 2012), Japan and the USA (Puonti, 2019), among others.

In addition to this introduction, the next section discusses the existing literature, providing a detailed view as for the methodology to be used, as the third section presents the analysis of the results, followed by the concluding remarks. 


\section{Econometric Methodology and Dataset}

Bayesian estimation method, when treating the parameters as sort of random variables, imposes significant probability distributions to priors to a complete set of VAR model coefficients, as to obtain parsimony in the number of parameters to be estimated. Thus, the use of BVAR entails more powerful estimators and, as consequence, it is an estimating model supported by great predictive means. Unlike unrestricted VAR, BVAR does not get so many parameters to be estimated, and it also imposes some quantitative restrictions that exclude certain parts as for parameter space. However, a proper choice of priors should press some structure on the VAR that reflects the nature and process of generating data.

In this article, we are in line with Ouliaris et al. (2016). Consider a standard regression model with coefficients $\beta_{s}$ and a variance-covariance matrix $\Sigma_{e}$ unknown:

$$
z_{t}=x_{t}^{\prime} \beta+e_{t}
$$

where $\mathrm{x}_{\mathrm{t}}=\left(\mathrm{z}_{\mathrm{t}-1}, \mathrm{z}_{\mathrm{t}-2}, \ldots, \mathrm{z}_{\mathrm{t}-\mathrm{p}}\right.$, exogenous variables $)$ and $e_{t} \sim$ iid $N\left(0, \Sigma_{e}\right)$.

Given a prior distribution $\beta$ condicional and $\Sigma_{e}, p\left(\beta \mid \Sigma_{e}\right)$, likelihood function, $L\left(z \mid \beta, \Sigma_{e}\right)$, Bayes theorem is said to combine them in order to deploy posterior distribution, $p\left(\beta \mid \Sigma_{e}, z\right)$, as follows:

$$
p\left(\beta \mid \Sigma_{e}, z\right)=L\left(z \mid \beta, \Sigma_{e}\right) p\left(\beta \mid \Sigma_{e}\right) / p(z)
$$

The term below is called normalizing constant

$$
p(z)=\int p(z \mid \beta) p(\beta) d \beta
$$

Accordingly, equation (2) stands for:

$$
p\left(\beta \mid \Sigma_{e}, z\right) \propto L\left(z \mid \beta, \Sigma_{e}\right) p\left(\beta \mid \Sigma_{e}\right)
$$

To settle BVAR, as to put forward the analysis as for IRFs, VD along with prediction, it is urged to posit $\beta$ e $\sum_{e}$ estimators. $\beta$ estimator consists of its posterior mode, which can be founded by means of the following expression maximization:

$$
C(\beta)=\ln \left[L\left(z \mid \beta, \Sigma_{e}\right)\right]+\ln \cdot p\left(\beta \mid \Sigma_{e}\right)
$$

Another estimator is the $\beta$ posterior mean. When posterior highlights a normal distribution, mode and mean are equal. However, they may be different in other cases. Bayesian method can find posteriors to a number of different types of priors via simulation. However, for simplicity, assume that prior $\beta$ is normally distributed, then:

$$
p(\beta) \sim \mathrm{N}(\underline{b}, \underline{V})
$$

$\beta$ posterior will be distributed in normal terms:

$$
p\left(\beta \mid \Sigma_{e}, z\right) \sim \mathrm{N}(b, V)
$$

$\beta$ mode and mean estimated will be given by a matrix of the weighted average to OLS estimation along with priors established in the current research. So the $\beta$ posterior is:

$$
\bar{b}=\left[\underline{V}^{-1}+\Sigma_{e}^{-1} \otimes\left(X^{\prime} X\right)\right]^{-1}\left[\underline{V}^{-1} \underline{b}+\left(\Sigma_{e}^{-1} \otimes X^{\prime}\right) y\right]
$$

From (8), notice that the $\bar{b}$ estimator depends on variance-covariance matrix of random errors, $\Sigma_{\mathrm{e}}$. Then, such matrix has to be estimated. This can be done using OLS information, as follows:

$$
V=\left[\underline{V}^{-1}+\Sigma_{e}^{-1} \otimes\left(X^{\prime} X\right)\right]^{-1}
$$

Another way to obtain information about the matrix $\Sigma_{e}$ is to produce Bayesian estimates about it, which will require establishing priors on the variance matrix in question.

A variety of Bayesian priors have been developed for use in vector autoregressive models, such as Litterman/Minnesota, WishartNormal, Sims-Zha Normal Wishat, Sims-Zha Norma Flat, and others. We choose Litterman/Minnesota method. In this method, $\beta$ prior is usually distributed and conditional to $\Sigma_{e}$ matrix. It is mandatory to know the way the variance-covariance matrix of random errors is estimated. There are three possibilities: (i) use the residual variance estimates of an adjusted $\operatorname{AR}(1)$ model to each series; (ii) replace $\Sigma_{e}$ by its estimate, $\hat{\Sigma}_{e}$, whose diagonal elements, $\sigma_{i}^{2}$, are OLS estimates of the error variances to a VAR; and (iii) estimate the complete $\Sigma_{e}$ implied by the VAR (the df argument controls whether the initial residual covariance is to be corrected for the available degrees of freedom). In the current work we follow (iii) as to obtain variance-covariance matrix of random errors or $\Sigma_{e}$ estimates to a VAR model. Moreover, such possibility is not the best option, once estimated matrix may be singular, that is, there may not be enough information when the amount of variables and lags in the VAR are so large.

Once established how matrix will be estimated $\Sigma_{e}$, then $\beta$ prior must be calibrated: $\mu_{1}, \lambda_{1}, \lambda_{2}$ and $\lambda_{3}$, is a 
set of hyperparameters. $\mu_{1}$ is $\underline{b}$ prior mean. It could be the case to equate such prior to 1 or even closer to 1 in order to capture sort of persistence in economic and financial time series. In this study $\mu_{1}=1$ was used, becauseof the seven variables that make up the BVAR, five are 1st order integrated, I(1). Two of them, inflation and inflation prediction are stationary, I(0). However, if the VAR series are in difference or in growth rate, $\mu_{1}=0$ would be convenient. $\lambda_{1}$ is the global adherence over the variance (first lag) and controls the global adherence of $\beta$, and should be close to zero if there is more certainty about the prior. That is, by establishing $\lambda_{1}=0.1$, the prior's information is allowed to dominate the sample information. In such case, the prior is relatively strong. (Note 4 ) We regard $\lambda_{1}=6$, which allows both the calibrated prior value and the sample to play a significant role in the quality of BVAR adjustment.

On the other hand, $\lambda_{2}$ happens to be the relative adherence concerning variance of other variables. $\lambda_{2}$ controls the importance of the lag of variable $j$ in the $i$-th BVAR equation, with $i \neq j$, and is called cross-variable weights. If cross-lags play a relevant role in each equation inner the model, then $\lambda_{2} \cong 1$, otherwise $\lambda_{2} \cong 0$. (Note 5) $\lambda_{2}=0.99$ was the calibration used for this prior in the estimated BVAR, as it is assumed that cross-lags play a relevant role in each model equation, given the dynamic intercommunication in the impulse variables of the transmission channels and the response variables, GDP and Inflation, from the BVAR.

Finally, $\lambda_{3}>0$ represents the relative adherence of the variance of the lags of the variables and so is the decline rate of these lags. If $\lambda_{3}=1$, then there is a linear decline in lags. Therefore, this prior was calibrated equal to unity. After calibrating BVAR priors, the quality of the established priors can be tested looking at BVAR prediction errors compared to prediction errors of an unrestricted (or standard) VAR. This test was performed and the BVAR forecast errors were mostly lower than the unrestricted VAR forecast errors (Note 6).

The model consists of seven variables. Five of them make up the traditional transmission channels of monetary policy (impulse variables): non-earmarked real credit balance (Credit) (Note 7); short-term interest rate (SELIC); inflation prediction (E(IPCA)); São Paulo Stock Exchange Index (Ibovespa); nominal exchange rate index, $\mathrm{R} \$ / \mathrm{US} \$$, sales/average to period (Exchange Rate); taken from IPEADATA, Central Bank of Brazil and Bloomberg. And two response variables: real gross domestic product (GDP) (Note 8) and the broad consumer price index (IPCA), both from IPEADATA. GDP, Ibovespa, Credit and Exchange Rate variables are in natural logarithm. Selic, IPCA and E(IPCA) variables are in percentage. Equation (1) is said to be, in a simplified way, the Bayesian VAR model to be estimated.

$$
Y_{t}=(G D P, I P C A, C R E D I T, \text { SELIC, E(IPCA), IBOVESPA, EXCHANGE RATE) }
$$

The model is adjusted using monthly data, from January 2009 to December 2019. The variables are used in level, although five variables that make up the model are $I(1)$. This seeks to avoid imposing possibly incorrect restrictions on the model, according to Sims and Uhlig (1991) and Stock and Watson (1990). That is, even with $I(1)$ variables, the residuals continue to be stationary, given the inclusion of differences of variables in level in the model (Hamilton, 2020) (Note 9).

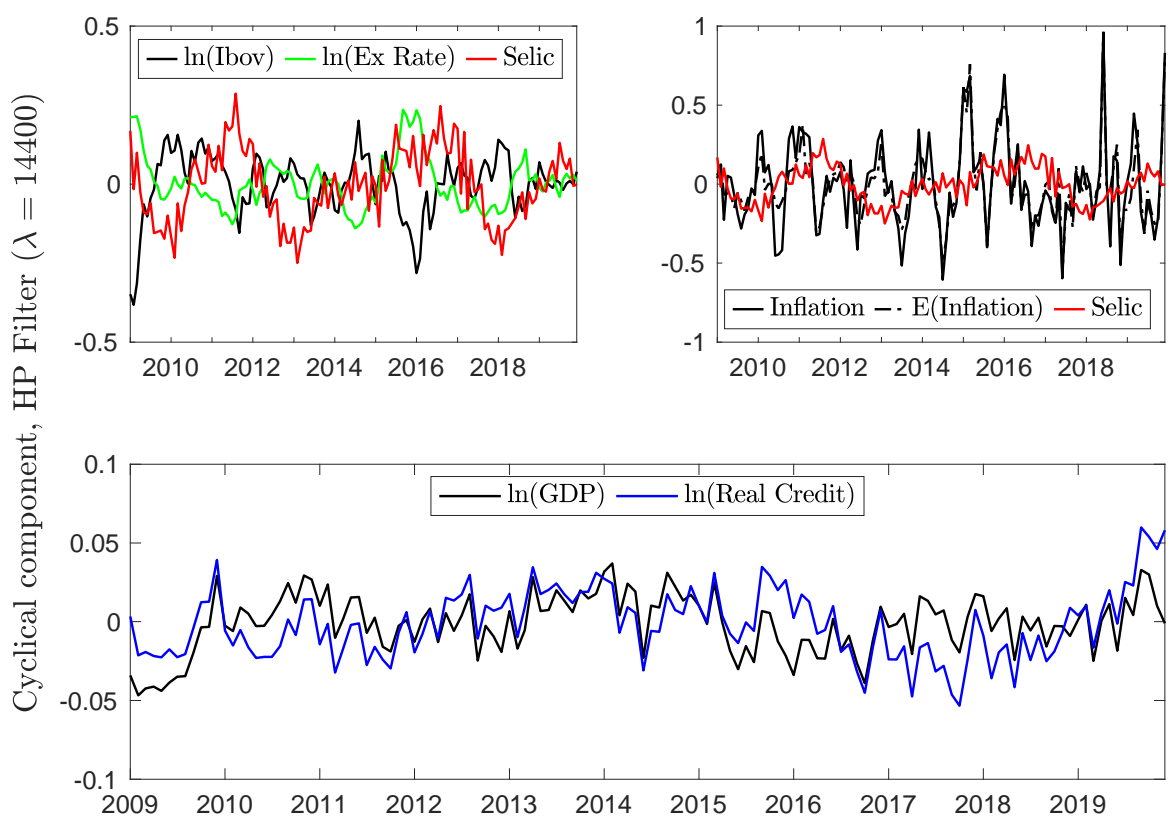

Figure 1. Cyclic component of moving between variables 
Monthly cyclical component between the model's variables is seen in Figure 1. The first panel presents the variables that denote the price of assets, the exchange rate and the interest rate. Visually, it is clear that there is a strong negative correlation between the Ibovespa and the exchange rate $(-0.73)$ and a weaker negative correlation between the former and the interest rate $(-0.27)$, which is in line with economic theory. The second panel brings inflation and its expectations and the interest rate. As the variables are taken on monthly scale not on 12-month accumulated one, although positive correlation between cyclical components is visible, the correlation coefficient value is close to zero given the high inflation dispersion. Ultimately, last panel displays, as expected, a strong correlation between GDP and credit (0.80). Several studies indicate the consensus that private credit is considered pro-cyclical (see, for instance, Bernanke \& Gertler, 1990; Holmstrom \& Tirole, 1997; Kiyotaki \& Moore, 1997; Diamond \& Rajan, 2005).

\section{Estimation and Results}

Bayesian VAR estimation process was carried out following conventional routine of multivariate time series studies, namely: unit root, ADF, PP and KPSS tests were performed, which showed that only inflation and inflation prediction variables are $I(0)$, stationary; and the optimal number of lags used in the model was determined taking into account Schwartz, Akaike, Hannan-Quin information criteria and the elimination of the residual autocorrelation problem, which established that a BVAR with six lags would be the most suitable (Note $10)$.

A BVAR, with six lags, was estimated based on equation (1). The model is well specified, given priors calibrated, that is, $\mu_{1}=1, \lambda_{1}=6, \lambda_{2}=0.99$ and $\lambda_{3}=1$; in a nutshell, the model does not get residual autocorrelation problem (Table 1) and the prediction errors (within the sample) of BVAR are lower than prediction errors of the unrestricted VAR (see Appendix), beyond its robustness (Note 11).

Table 1. Residual Autocorrelation Likelihood Ratio Test.

\begin{tabular}{ccccccc}
\hline Lag & LRE* stat & df & Prob. & Rao F-stat & Df & Prob. \\
\hline 1 & 70.27830 & 49 & 0.0247 & 1.477644 & $(49,359.8)$ & 0.0253 \\
2 & 59.74062 & 49 & 0.1399 & 1.238454 & $(49,359.8)$ & 0.1416 \\
3 & 62.69158 & 49 & 0.0905 & 1.304775 & $(49,359.8)$ & 0.0918 \\
4 & 56.99084 & 49 & 0.2023 & 1.177112 & $(49,359.8)$ & 0.2044 \\
5 & 55.69135 & 49 & 0.2376 & 1.148276 & $(49,359.8)$ & 0.2399 \\
6 & 56.23156 & 49 & 0.2224 & 1.160251 & $(49,359.8)$ & 0.2247 \\
7 & 63.72803 & 49 & 0.0769 & 1.328190 & $(49,359.8)$ & 0.0781 \\
8 & 50.15858 & 49 & 0.4272 & 1.026590 & $(49,359.8)$ & 0.4299 \\
9 & 49.80110 & 49 & 0.4412 & 1.018788 & $(49,359.8)$ & 0.4439 \\
\hline
\end{tabular}

Source: Authors elaboration.

\subsection{Impulse Response Functions}

IRFs supported by the generalized method (Generalized IRFs) points the GDP responses to a positive shock/impulse of an innovation with respect to one standard deviation in each variable that make up traditional transmission channels of monetary policy, that is, real credit, short-term interest rate, inflation expectation, São Paulo stock exchange index, and nominal exchange rate, respectively (Note 12).

Figure 2 shows that a positive shock (or an innovation of one standard deviation) of non-earmarked credit results, in the first month, in a significant increase in GDP. From the second to the fifth month there is a slowdown in this growth. However, after the fifth month, GDP returns to its natural growth trajectory (or steady state), reaching a new peak in the seventh month. After the peak of the seventh month, GDP shows a downward trajectory until the eleventh month, but it reverses this downward trajectory and remains above its natural trajectory after twelve months. (Note 13) Therefore, the variable in question does not have a significant impact on GDP. This can be explained as follows: the non-earmarked credit/GDP ratio was approximately $28 \%$ in the period from January 2009 to December 2015; in the period from January 2016 to December 2018, this ratio dropped to around 25\%; and returned to $28 \%$ in December 2019. It can be said that non-earmarked credit is not very representative for the purpose of determining aggregate demand, consumption and investment, and, consequently, of GDP (see, for instance, Bogdanski et al., 2000). On the other hand, at the international level, mainly in developed countries, the non-earmarked credit transmission channel plays an important role in the GDP dynamics. In the Brazilian case, however, this channel plays a secondary role (Mendonça, 2001). 
In the first seven months, the GDP reaction to an increase in the short-term interest rate does not outline a well-defined dynamic. It is observed that a positive shock/increase in the SELIC gets an external lag - common to monetary policy decisions - of seven months so that its negative effect on GDP achieve consistency. However, from seventh to twelfth month, GDP is always below its natural path, which is in line with monetary theory. That is, assuming the existence of a term structure of interest rate, which establishes a defined relationship between short, medium and long-term interest rates, then monetary policy authority may use short-term interest rate to affect remaining the ones. Therefore, an increase in the short-term interest rate (SELIC) (Note 14) leads to an increase in the long-term interest rate, resulting in a reduction in aggregate consumption and investment, hence, in GDP. However, it is noted that there is a low elasticity concerning GDP in relation to the interest rate (Note 15).
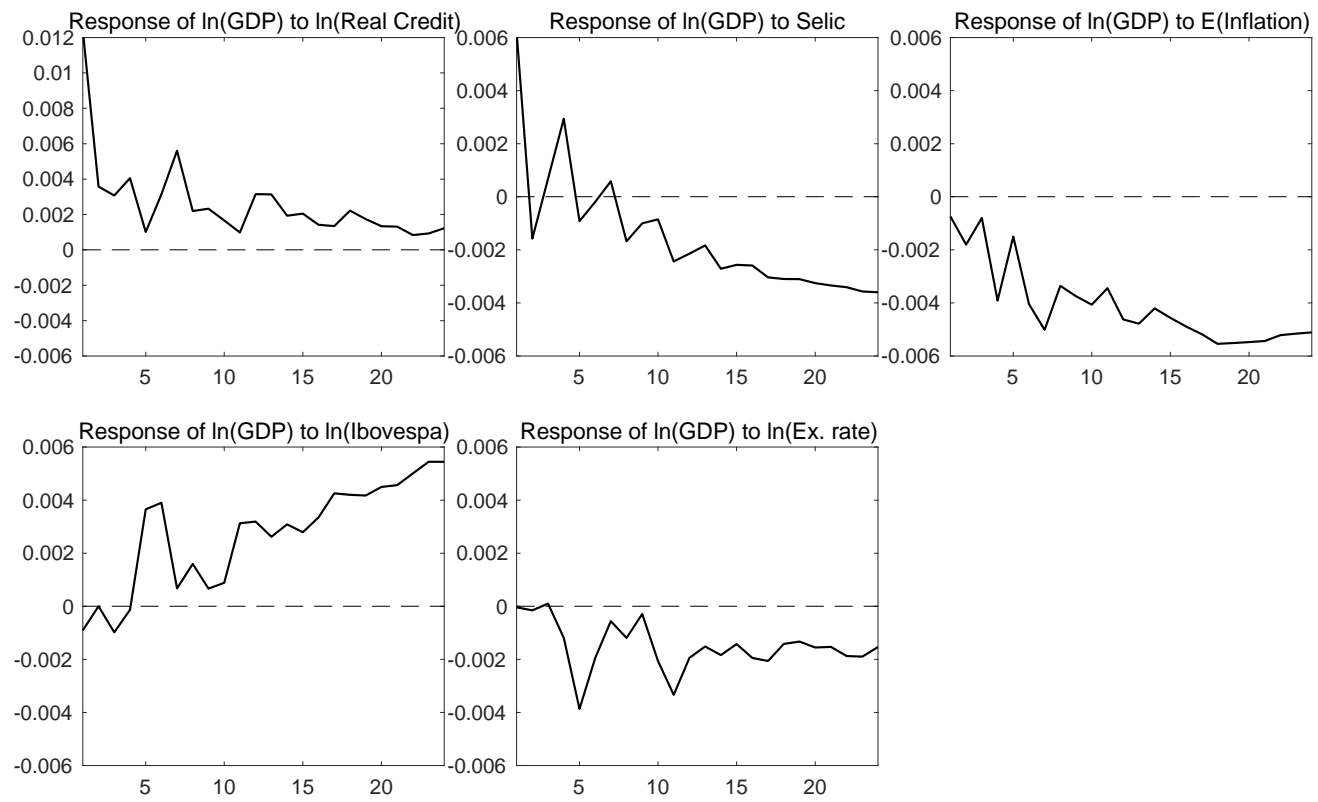

Figure 2. GDP response to 1 standard deviation innovations in the remaining variables

A possible way of analyzing how GDP reacts to a positive shock in inflation predictions is via the so-called Fisher effect (Mishkin, 2009). Fisher effect seeks to show that the economy's nominal interest rate $(i)$ is the sum of the real interest rate $(r)$ and the expected inflation rate $\left(\pi^{e}\right): i=r+\pi^{e}$. Thus, nominal interest rate must change (increase or decrease) whenever there are changes in the real interest rate or inflation predictions. Therefore, an increase in inflation predictions leads to an increase in short-long-term interest rates, which will reduce aggregate consumption and investment, as consequence, GDP. (Note 16) It can be seen in Figure 2 that this is actually what happens after a positive shock of one standard deviation in inflation predictions, GDP gets a consistent declining path that extends over a period up to one year.

A positive shock to the Ibovespa (asset prices) results in the following short-term dynamics of GDP: it remains relatively stable in the first four months, rising from the end of the fourth to the end of the sixth month, from the seventh to the end of the ninth month it remains stable and from the tenth month it gets a moving up path, remaining above its usual path after 12 months, that is, there is no convergence in the short term. It is observed that the effect of asset prices upon GDP is in line with the theory, in terms of signal. However, from a quantitative point of view, the small participation of individuals in the Brazilian capital market, around $0.5 \%$ in mid-2019, it does not allow the action of the wealth effect, in its fullness, when asset prices increase. (Note 17) To be precise, if households expended their resources mainly in stocks, then an increase in asset prices would result in an increase in their wealth, leading to an increase in aggregate consumption along with GDP. Getting closer to this situation, in the manner of Tobin's $q$ (Tobin, 1969), we get: when the demand for shares increases, asset prices increase, hence, Tobin's $q$ increases, stimulating an increase in aggregate investment and GDP. Once again, low participation of households in the capital market does not allow for a significant demand for variable income assets, a sort of cheaper way for companies to finance their investments. Therefore, there is no stimulus to increase investment, which results in an irrelevant effect of a positive asset price shock upon GDP.

An exchange rate depreciation, in turn, inherent to a positive exchange rate shock, needs three months to 
negatively affect GDP. Overall, GDP remains close to its steady-state path. Except the fifth and tenth months, where the domestic product falls a little more seriously. As such, this means that exchange rate does not significantly affect GDP. A possible explanation regarding the negative effect of the nominal exchange rate depreciation on output is: an exchange rate depreciation entails an increase in the costs of intermediate goods and imported machinery, and also increases the foreign currency debt of domestic companies. Hence this results in a negative effect on domestic productive sectors, such as industry, etc., and so upon GDP.

It is observed in Figure 3 that a positive shock of non-earmarked credit does not significantly impact inflation. Inflation remains in the approximate neighborhood of its typical path (or steady- state) over almost one year, except the first two months. This fact can be explained as follows: it was seen previously, that non-earmarked credit is not representative to the purpose of determining aggregate demand, consumption and investment, hence, GDP (Bogdanski et al., 2000). Therefore, non-earmarked credit, by not applying conspicuous pressure on aggregate demand, is unable of causing significant pressure on inflation. Therefore, both GDP and inflation get a low elasticity in relation to this variable.
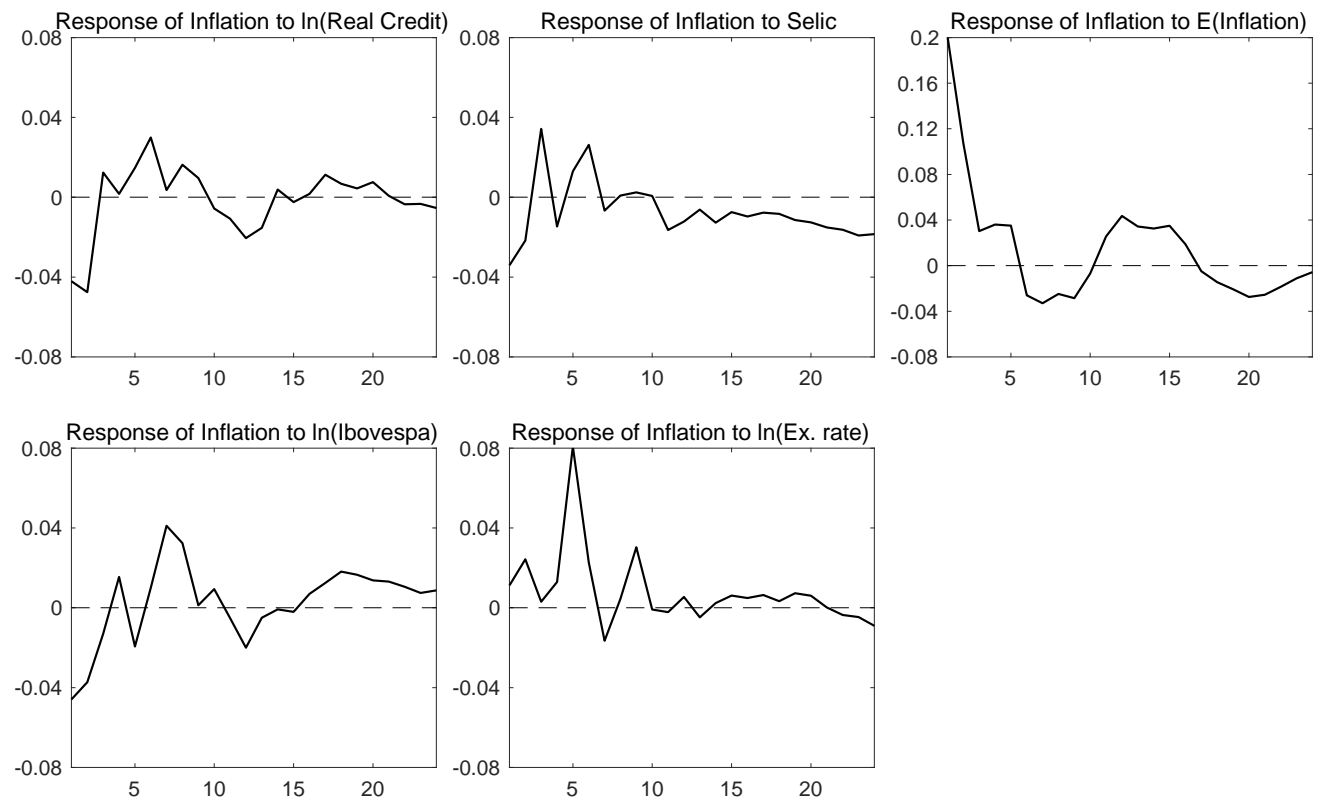

Figure 3. Inflation response to 1 standard deviation innovations in the other variables

The term structure of the interest rate theory takes for granted that an increase in the short-term interest rate entails in an increase in the long-term interest rate, which leads to a reduction in aggregate consumption and investment, along with GDP and inflation. A positive interest rate shock means a reduction in inflation in the first two months, this shows that there is no trouble in the estimated model "price puzzle". (Note 18) In the third- and sixth-month inflation emphasizes a positive reaction to an increase in the interest rate, but from the seventh to the twelfth month inflation remains close to its steady-state temporal path (Figure 3). To sum up, inflation as well as GDP also get low elasticity in relation to the interest rate (Note 19).

Inflation expectations are of fundamental importance in decisions, in the contemporary period, of wage adjustments, by workers, and prices, by companies. Assuming that economic agents are rational, they make their decisions about wage and price adjustments based on all available information, taking current and expected future economic policies (Barbosa et al., 2019). The current inflation is expected to react positively to an increase in expected inflation. Positive shock of one standard deviation in inflation predictions results in a significant increase in inflation in both first months, but starts a downward path until the beginning of the third month. From the third to the fifth month, inflation remains above its steady-state path; from the beginning of the sixth to the beginning of the tenth month, it falls below its usual path (exactly the only period in which the empirical evidence does not agree with the theory). As of the end of the tenth month, it resumes a growth path, beyond its steady-state path, which has been retained for a period beyond twelve months. Therefore, as a whole, positive shock to inflation predictions entails positive effect on current inflation, except the period from the beginning of the sixth to the beginning of the tenth month. 
We have already seen that increase in asset prices does not get a significant effect on wealth (i.e, not significantly boosting consumption) even in Tobin's $q$ (investments are not significantly boosted). Therefore, a positive shock to asset prices does not result in relevant increases in aggregate demand or in Brazilian GDP. This can be justified by the low participation of individual investors in the equity market (see Note 17). As a positive asset price shock did not result in a significant increase in aggregate demand and GDP, then this shock will not lead to a significant increase in inflation. As it is showed in Figure 3, inflation does not get a well-defined temporal path after a positive asset price shock, it gets a significant drop in the first month and remains below its steady-state path until the third month. In the fourth month, it is above this path, but in the fifth month it returns to below its typical path. From the sixth to the end of the eighth month, it is beyond this path, on which it remains from the ninth to the eleventh month, when it returns to a path lower than that of the steady-state from the twelfth month on.

Finally, a positive exchange rate shock on inflation can be viewed based on the exchange rate pass-through effect, which shows the inflation response to exchange rate depreciation (positive exchange rate standard deviation shock). (Note 20) The greater the depreciation of the real vis-à-vis the dollar - the increase in the exchange rate (R\$/US\$) - the greater will be inflation. This happens because there is an increase in the price of oil, which is quoted in dollars, which results in an increase in the price of gasoline, which leads to an increase in the prices of intermediate and final goods; and there is a reduction in the number of competing products, reducing imports and increasing aggregate demand, resulting in inflationary pressure. (Note 21) It can be seen in Figure 3 that in the face of a positive exchange rate shock, inflation remains relatively stable around its steady- state path in the first two months. From the third to the end of the sixth month, inflation increases significantly, reaching a maximum exchange rate pass-through in the fifth month. In the seventh month, inflation falls below its common equilibrium path (or steady-state path). In the period from the eighth to the tenth month, there is another episode of exchange pass-through, a slightly smaller magnitude, with a local maximum in the ninth month. From the tenth month onwards, inflation converges to the immediate locality of its steady-state.

\subsection{Variance Decomposition}

In Figure 4 we see the variance decomposition of forecast error (VD) to four different forecast horizons, namely: two, four, twelve and eighteen months. Each column shows, as for each of the response variables, GDP and inflation, the amount of the forecast error that is explained by structural shocks to each of the seven variables that make up the model, duly listed in the legends. Hence, regard each forecast horizon, the sum of entries in a given column equals $100 \%$.

In the short-term or a year, Brazilian GDP gets its forecast errors justified by its own shocks, on average $70 \%$. However, in the medium term or 18 months, its forecast errors are justified by its own shocks, around 35\%, also by inflation shocks, $34 \%$, and by interest rate shocks, $20 \%$. The other monetary policy transmission channels do not get, in the short-medium term, a significant influence on GDP forecast errors, except the IBOVESPA, which explains $6 \%$ of the forecast error to the variable under analysis, in 18 months.

Inflation forecast errors are viewed, in the short-term, mainly by its own shocks, on average $85 \%$. In the medium term, inflation forecast errors are justified $68 \%$ by inflation, $6 \%$ by GDP and the other transmission channels participate individually, around 6\%.
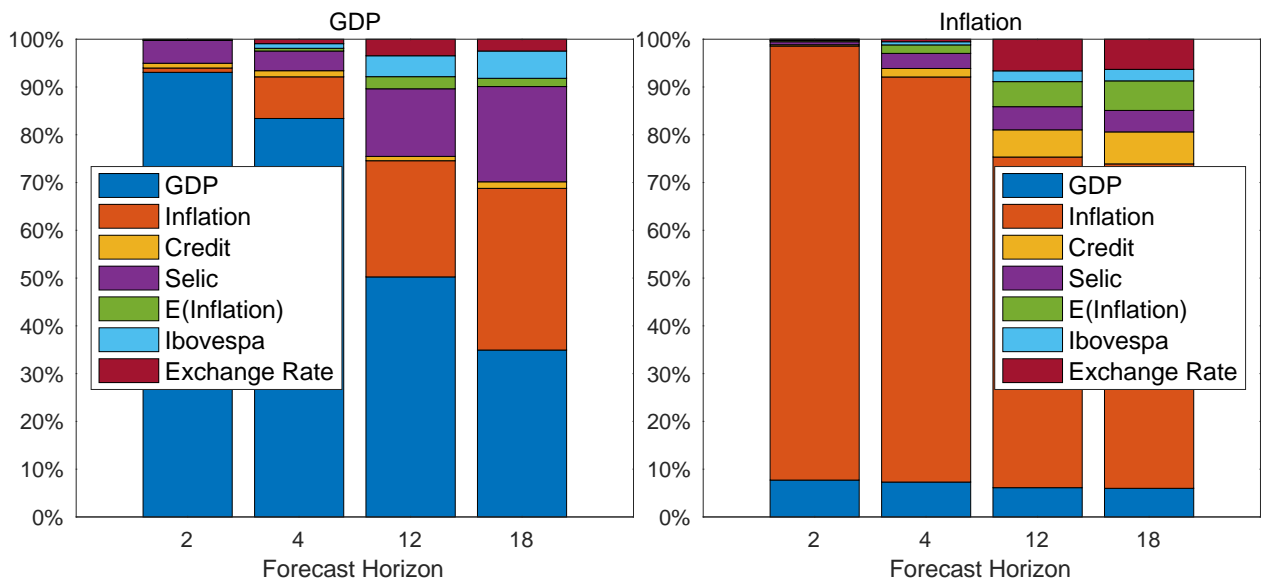

Figure 4. Variance Decomposition - Amount of variance precision error per variable 


\subsection{Robustness Analysis}

The robustness analysis was performed in order to include commodity price variable in the estimated BVAR. (Note 22) The model was estimated, assuming that the commodity price variable is the most exogenous BVAR variables. It results in the following ordering of the autoregressive vector: i) $\ln$ (Commodity Prices); ii) $\ln (\mathrm{GDP}$ ); iii) $\ln ($ Credit); iv) Selic; v) E(IPCA); vi) $\ln$ (Ibovespa); and vii) $\ln ($ Exchange Rate). Six lags and the same priors put in the BVAR. And it was analyzed whether there are relevant changes in the dynamics of IRFs (generalized) as for BVARs with and without commodity prices. When comparing Figures 5 and 2, it is noted that the inclusion of commodity prices into BVAR did not result in significant changes in the (generalized) IRFs, which captures the shocks of the transmission channels on the Brazilian GDP. Performing the same comparison as for Figure 6 and 3, we see that the inclusion of commodity prices into the Bayesian VAR does not lead to any relevant change in the dynamics of the shocks of the monetary policy transmission channels on inflation, measured by the broad consumer price index (IPCA).
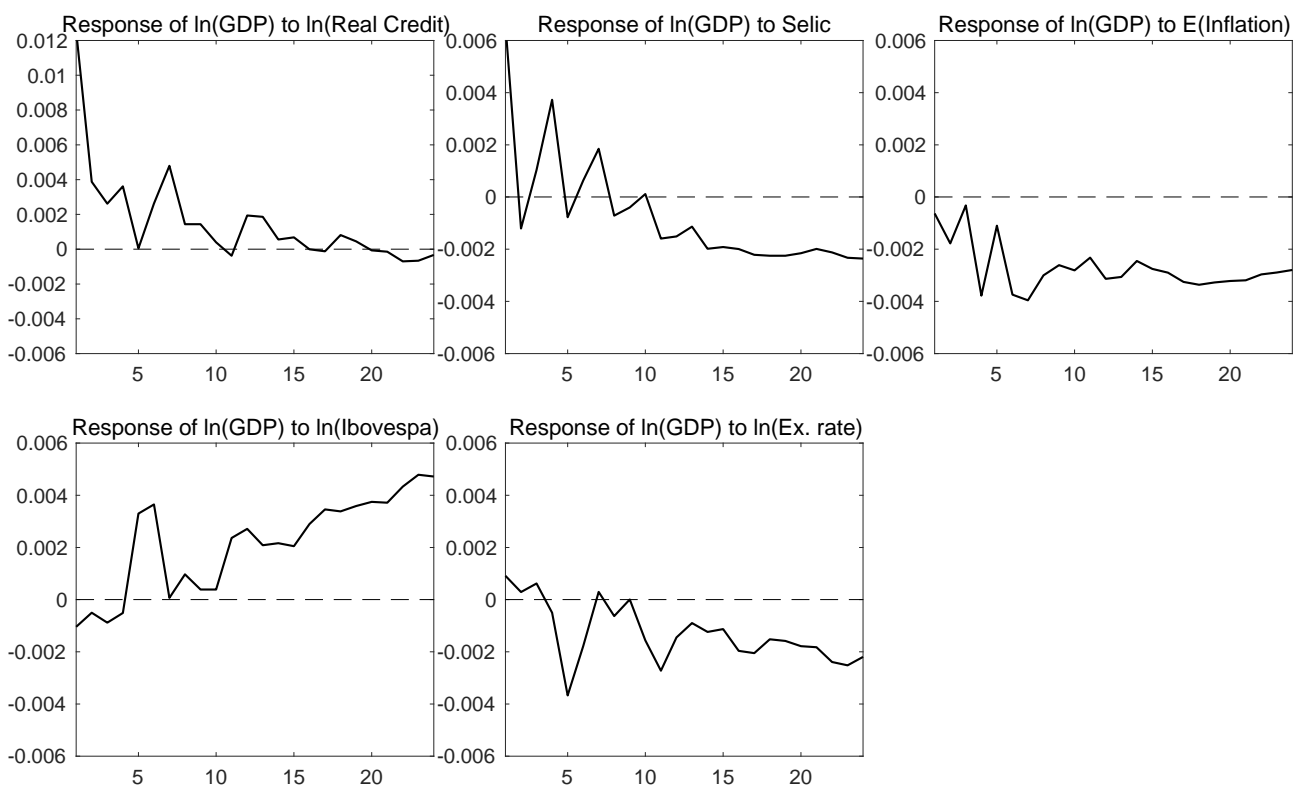

Figure 5. GDP response to 1 standard deviation innovations in the remaining variables
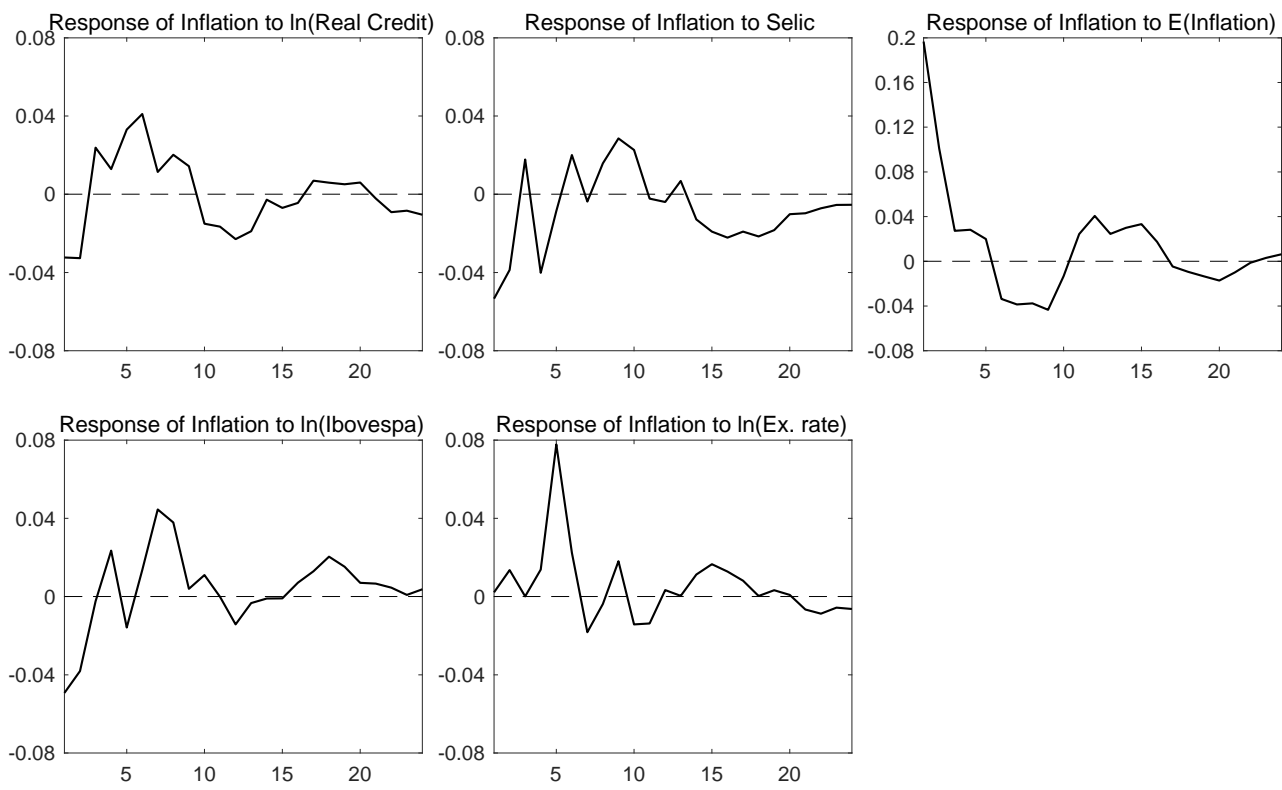

Figure 6. Inflation response to innovations of 1 standard deviation in the remaining variables 
Accordingly, the BVAR model is robust and the results presented in the current study are relevant as a way of understanding the dynamic relationship between GDP, inflation and the traditional transmission channels of monetary policy in Brazil.

\section{Conclusion}

In this work, it was analyzed, through the impulse-response functions (FIRs) and the variance decomposition (DV) of a Bayesian vector autoregressive (BVAR) model, using in principle the priors of Minnesota (Litterman, 1986), the interaction dynamics of the traditional transmission channels of monetary policy (short-term interest rates, credit, asset prices, inflation expectations and exchange rates) with the real gross domestic product (GDP) and inflation for the Brazilian economy.

As seen, analyzes revealed that GDP response to a positive shock in non-earmarked credit does not get significant impact on GDP, which is due to the low free credit/GDP ratio throughout the analysis, so that free credit is not the key to the purpose of determining aggregate demand, consumption and investment, and, hence, GDP (Bogdanski et al., 2000). On the other hand, an increase in the short-term interest rate (SELIC) leads to an increase in the long-term interest rate, resulting in a reduction in aggregate consumption and investment, hence, in GDP. However, it is noted that there is a low elasticity of GDP in relation to the interest rate. After a positive shock to inflation prediction, GDP gets a consistent declining path that extends over a period of more than one year (a fact in line with the Fisher effect). It also appears that there is no stimulus to increase economic activity after a positive assets' price shock, i.e, a fact that derives from the low participation of families in the capital market, making the wealth effect non-significant. Finally, a positive exchange rate shock does not significantly affect the GDP, but pressures it to remain below its usual path beyond two years. A possible explanation due the negative effect of the nominal exchange rate depreciation on output is that an exchange rate depreciation entails an increase in the costs of intermediate goods and imported machinery, in addition to increasing the foreign currency debt of domestic companies, which results in a negative effect on productive sectors, such as industry, hence, on GDP.

Furthermore, the analyzes as for inflation response to shocks in the variables that make up traditional transmission channels of monetary policy presented results in line with economic theory. A positive shock to non-earmarked credit, by not exerting significant pressure on aggregate demand, is unable to cause significant pressures on inflation. Therefore, both GDP and inflation get a low elasticity in relation to free credit (Bogdanski et al., 2000). A positive interest rate shock, in turn, entails a reduction in inflation in the first two months, which demonstrates that the "price puzzle" issue does not happen to take place in the estimated model. From the seventh to the twelfth month, inflation remains close to, but still below, its steady-state temporal path. Inflation does not get a well-defined time path after a positive shock on assets' price, that is, as explained above via the Tobin's q wealth effect: an asset price shock does not result in a significant increase in GDP, implying that such a shock will not lead to a significant increase in inflation. Finally, given a positive exchange rate shock, inflation remains relatively stable around its steady-state path in the first two months, but from the third to the end of the sixth month, inflation increases significantly, reaching the maximum pass-through exchange rate in the fifth month. In the seventh month, inflation falls below its steady-state path. In the period from the eighth to the tenth month, there is another episode of exchange pass-through, of a slightly smaller magnitude, with a local maximum in the ninth month. From the tenth month onwards, inflation converges to the immediate locality of its steady-state.

With respect the variance decomposition of the forecast error (VD), the GDP, in the short- term or up to one year, gets its forecast errors mostly justified by its own shocks, on average $70 \%$. However, in the medium term or 18 months, also its forecast errors are justified by its own shocks, around 35\%, (inflation shocks, 34\%; interest rate shocks, 20\%). The other monetary policy transmission channels do not result in a significant influence on GDP forecast errors, except the IBOVESPA, which explains $6 \%$ of the forecast error over the longer horizon. Inflation forecast errors are explained, in the short-term, mainly by their own shocks, on average $85 \%$. In the medium term, inflation forecast errors are explained $68 \%$ by inflation itself, 6\% by GDP and another transmission channels participate individually around $6 \%$. The inclusion of the variable that measures commodity prices did not result in significant changes, therefore, the results of the estimated BVAR model is relevant as a way of understanding the dynamic relationship between GDP, inflation and the traditional transmission channels of monetary policy in Brazil.

Guided by the same agenda, as a proposal for future work, is the use of different priors methodologies, such as Wishart-normal and Sims-Zha, among others, in order to verify the smallest forecast errors; also to identify the best model that explains changes as for the variables in the analysis of monetary policy transmission channels, 
which may in turn support better monetary policy decision-making.

\section{Acknowledgments}

We thank the participants at the Winter School 2021, organized by the Centre for Development Economics (CDE) jointly with the Econometric Society at the Delhi School of Economics, for helpful suggestions and comments. We thank also CNPq for financial support. Declarations of interest: none. All remaining errors are our own.

\section{References}

Álvarez, L. J., Ballabriga, F. C. et al. (1994). BVAR models in the context of cointegration: A Monte Carlo experiment. Tech. rep., Banco de España.

Auel, M. C., \& de Mendonça, F. C. (2011). Macroeconomic relevance of credit channels: Evidence from an emerging economy under inflation targeting. Economic Modelling, 28, 965-979. https://doi.org/10.1016/j.econmod.2010.11.012

Bańbura, M., Giannone, D., \& Reichlin, L. (2010). Large Bayesian vector auto regressions. Journal of Applied Econometrics, 25, 71-92. https://doi.org/10.1002/jae.1137

Barbosa, K., Fetter, S., \& Rocha, B. D. P. (2019). An empirical procedure to evaluate monetary management under exogenous changes in the money supply. Applied Economics, 51, 1248-1267. https://doi.org/10.1080/00036846.2018.1527443

Bernanke, B., \& Gertler, M. (1990). Financial fragility and economic performance. The Quarterly Journal of Economics, 105, 87-114. https://doi.org/10.2307/2937820

Bloor, C., \& Matheson, T. (2010). Analysing shock transmission in a data-rich environment: A large BVAR for New Zealand. Empirical Economics, 39, 537-558. https://doi.org/10.1007/s00181-009-0317-3

Bogdanski, J., Tombini, A. A., \& Werlang, S. R. D. C. (2000). Implementing inflation targeting in Brazil. Werlang, Sergio R., Implementing Inflation Targeting in Brazil (July 2000). Banco Central do Brasil Working Paper. https://dx.doi.org/10.2139/ssrn.247507

Borys, M. M., Horváth, R., \& Franta, M. (2009). The effects of monetary policy in the Czech Republic: An empirical study. Empirica, 36, 419. https://doi.org/10.1007/s10663-009-9102-y

Catão, L., Laxton, D., \& Pagan, A. (2008). Monetary transmission in an emerging targeter: The case of Brazil. IMF Working Papers, 2008. https://doi.org/10.5089/9781451870497.001

Céspedes, B., Lima, E., \& Maka, A. (2008):. Monetary policy, inflation and the level of economic activity in Brazil after the Real Plan: stylized facts from SVAR models. Revista Brasileira de Economia, 62, 123-160.

Céspedes, L. F., \& Soto, C. (2005). Credibility and inflation targeting in an emerging market: Lessons from the chilean experience. International Finance, 8, 545-575. https://doi.org/10.1111/j.1468-2362.2005.00169.x

Christiano, L. J., Eichenbaum, M., \& Evans, C. L. (1999). Monetary policy shocks: What have we learned and to what end? Handbook of Macroeconomics, 1, 65-148. https://doi.org/10.1016/S1574-0048(99)01005-8

Coelho, C. A., De Mello, J. M., Garcia, M. G., \& Galindo, A. J. (2010). Identifying the bank lending channel in brazil through data frequency [with comment]. Economía, 10, 47-79.

Cogley, T., \& Sargent, T. J. (2005). The conquest of US inflation: Learning and robustness to model uncertainty. Review of Economic Dynamics, 8, 528-563. https://doi.org/10.1016/j.red.2005.02.001

De Mello, L., \& Pisu, M. (2010). The bank lending channel of monetary transmission in Brazil: A VECM approach. The Quarterly Review of Economics and Finance, 50, 50-60. https://doi.org/10.1016/j.qref.2009.09.006

Diamond, D. W., \& Rajan, R. G. (2005). Liquidity shortages and banking crises. The Journal of Finance, 60, 615-647. https://doi.org/10.1111/j.1540-6261.2005.00741.x

Doan, T., Litterman, R., \& Sims, C. (1984). Forecasting and conditional projection using realistic prior distributions. Econometric Reviews, 3, 1-100. https://doi.org/10.1080/07474938408800053

Fernandes, M., \& Toro, J. (2005). O mecanismo de transmissão monetária na economia brasileira pós-Plano Real. Revista Brasileira de Economia, 59, 5-32.

Hamilton, J. D. (2020). Time series analysis. Princeton university press.

Holmstrom, B., \& Tirole, J. (1997). Financial intermediation, loanable funds, and the real sector. The Quarterly Journal of Economics, 112, 663-691. https://doi.org/10.1162/003355397555316 
Kiyotaki, N., \& Moore, J. (1997). Credit cycles. Journal of Political Economy, 105, 211-248. https://doi.org/10.1086/262072

Lima, A. M. C., \& Issler, J. V. (2003). A hipótese das expectativas na estrutura a termo de juros no Brasil: Uma aplicação de modelos de valor presente. Revista brasileira de economia, 57, 873-898.

Litterman, R. B. (1986). Forecasting with Bayesian vector autoregressions - five years of experience. Journal of Business \& Economic Statistics, 4, 25-38. https://doi.org/10.1080/07350015.1986.10509491

Lopes, L. S., Chauvet, M., \& de Lima, J. E. (2018). The end of Brazilian big inflation: Lessons to monetary policy from a standard New Keynesian model. Empirical Economics, 55, 1475-1505. https://doi.org/10.1007/s00181-017-1324-4

Luporini, V. (2008).The monetary transmission mechanism in Brazil: Evidence from a VAR analysis. Estudos Econômicos (São Paulo), 38, 7-30. https://doi.org/10.1590/S0101-41612008000100001

Mallick, S. K., \& Sousa, R. M. (2012). Real effects of monetary policy in large emerging economies. Macroeconomic Dynamics, 16, 190-212. https://doi.org/10.1017/S1365100511000319

Marçal, E. F., \& Pereira, P. L. V. (2007). A Estrutura a Termo das Taxas de Juros no Brasil: Testando a Hipótese de Expectativas. Pesquisa e Planejamento Econômico, 37.

Mendonça, H. F. (2001). Mecanismos de transmissão monetária e a determinação da taxa de juros: uma aplicação da regra de Taylor ao caso brasileiro. Economia e Sociedade, 10, 65-81.

Migliardo, C. et al. (2010). Monetary policy transmission in Italy: A BVAR analysis with sign restriction. Czech Economic Review, 4, 139-167.

Minella, A., \& Souza-Sobrinho, N. F. (2013). Monetary policy channels in Brazil through the lens of a semi-structural model. Economic Modelling, 30, 405-419. https://doi.org/10.1016/j.econmod.2012.04.027

Mishkin, F. S. (2009). Globalization, macroeconomic performance, and monetary policy. Journal of Money, Credit and Banking, 41, 187-196. https://doi.org/10.1111/j.1538-4616.2008.00204.x

Modenesi, A. D. M., \& De Araújo, E. C. (2013). Price stability under inflation targeting in Brazil: Empirical analysis of the monetary policy transmission mechanism based on a var model, 2000-2008. InvestigacióN EconÓMica, 72, 99-133.

Ouliaris, S., Pagan, A., \& Restrepo, J. (2016). Quantitative macroeconomic modeling with structural vector autoregressions-an Eviews implementation. Washington DC: IMF Institute for Capacity Development.

Peersman, G., \& Smets, F. (2001). The monetary transmission mechanism in the euro area: More evidence from var analysis (mtn conference paper). Available at SSRN 356269. https://dx.doi.org/10.2139/ssrn.356269

Pesaran, H. H., \& Shin, Y. (1998). Generalized impulse response analysis in linear multi-variate models. Economics letters, 58, 17-29. https://doi.org/10.1016/S0165-1765(97)00214-0

Pimentel, D. M., Luporini, V., \& Modenesi, A. D. M. (2016). Assimetrias no repasse cambial para a inflação: Uma análise empírica para o Brasil (1999 a 2013). Estudos Econômicos (São Paulo), 46, 343-372. https://doi.org/10.1590/0101-416146233dva

Puonti, P. (2019). Data-driven structural BVAR analysis of unconventional monetary policy. Journal of Macroeconomics, 61, 103131. https://doi.org/10.1016/j.jmacro.2019.103131

Sims, C. A. (2002). The role of models and probabilities in the monetary policy process. Brookings Papers on Economic Activity, 1-40.

Sims, C. A., \& Uhlig, H. (1991). Understanding unit rooters: A helicopter tour. Econometrica: Journal of the Econometric Society, 1591-1599. https://doi.org/10.2307/2938280

Sims, C. A., Stock, J. H., \& Watson, M. W. (1990). Inference in linear time series models with some unit roots. Econometrica: Journal of the Econometric Society, 113-144. https://doi.org/10.2307/2938337

Spulbăr, C., Niţoi, M., \& Stanciu, C. (2012). Monetary policy analysis in Romania: A Bayesian VAR approach. African Journal of Business Management, 6, 9957-9968. https://doi.org/10.5897/AJBM11.1150

Squeff, G. C. (2009). Repasse cambial reverso: Uma avaliação sobre a relação entre taxa de câmbio e IPCA no Brasil (1999-2007). Universidade Estadual do Rio de Janeiro: Dissertação de Mestrado.

Stock, J. H., \& Watson, M. W. (1990). Business cycle properties of selected US economic time series, 1959-1988. https://doi.org/10.3386/w3376 
Tejada, C. A. \& Silva, A. G. D. (2008). O pass-through das variações da taxa de câmbio para os preços dos principais produtos exportados pelo Brasil. Revista de Economia e Sociologia Rural, 46, 171-205. https://doi.org/10.1590/S0103-20032008000100008

Tobin, J. (1969). A general equilibrium approach to monetary theory. Journal of Money, Credit and Banking, 1, 15-29. https://doi.org/10.2307/1991374

Tomazzia, E. C., \& Meurer, R. (2009). O mecanismo de transmissão da política monetária no Brasil: Uma análise em VAR por setor industrial. Economia Aplicada, 13, 371-398. https://doi.org/10.1590/S1413-80502009000400002

\section{Notes}

Note 1. Details in Sims (2002).

Note 2. Due the studies provided by Doan et al. (1984) and Litterman (1986), the specification of a priori information is put forward by the idea according to which macroeconomic series follow random walks and that parsimonious models get better prediction rendered usually known as "Minnesota priors (or priors)". The term is adopted throughout this work. When necessary, other Bayesian priors can be used, for example Wishart-Normal, Sims-Zha Normal Wishart, Sims-Zha Norma Flat, among others.

Note 3. It will not be included 2020-2021 years into the current analysis as way of deviating the so-called Lucas' criticism. Data related to non-earmarked credit balance, individuals and companies cover March 2007 on, though the period from March 2007 to December 2008 and January 2020 to May 2021 is not contemplated due sub-prime crises and Covid-19 pandemic. We infer there has been a dramatic alteration in the structure of the economy, as consequence affecting moving patterns of BVAR variables.

Note 4 . In case $\lambda_{1} \geq 10$, the prior is said to be uncertain and the resulting estimates will be close to estimated coefficients of an unrestricted VAR (Ouliaris et al., 2016).

Note 5. If $\lambda_{2}=0$, then VAR collapses to a single-variable model.

Note 6. See appendix.

Note 7. As it is more directly related to real market conditions, the credit variable was used. In other words, free credit is mainly intended for household consumption and working capital financing for companies.

Note 8 . Such estimate is taken via interpolation of the quarterly values already released or those projected, and it is not a matter of calculating GDP based on primary information. This monthly calculation is put forward since official GDP calculated in Brazil by IBGE is released on a quarterly basis, while various economic information compiled by Central Bank is monthly.

Note 9. In multivariate time series models, the issue of cointegration is also analyzed. According to Álvarez et al. (1994), priors of the Litterman/Minisota type perform well in the presence of cointegration. The authors showed, in a Monte Carlo experiment, that adding long-term constraints to the priors does not improve, in non-asymptotic samples, the performance, predictive analysis, IRFS and VD of a Bayesian VAR. Using variables in level, however, implicitly allows for the possibility of co-integration between variables (Peersman \& Smets, 2001). In the article in progress, it was decided not to perform the cointegration test, even with $I(1)$ variables, since the purpose of the analysis using the autoregressive vector, VAR, SVAR or BVAR, is to determine the movements between the variables and not the estimated parameters. Therefore, the cointegration structure established between the variables is not an obstacle for the analysis of the IRFs and the VD of an estimated autoregressive vector (Sims et al., 1990).

Note 10. The authors have the corresponding results of the Bayesian VAR unit root and number of lags tests. Available upon request.

Note 11. The robustness test is in section 3.3.

Note 12. IRFs generalized method is robust to modification in the order variables enter into BVAR (Pesaran and Shin, 1998).

Note 13. A variable is said to be in natural path over time in the absence of shocks from other variables capable of modifying this trajectory. Natural path happens also to be the steady-state path of it.

Note 14. Whatever she is.

Note 15. Lopes et al. (2018) adopt a New Keynesian model estimated with Bayesian techniques related to 
1975-2012 period. The authors have not found evidence that GDP volatility is affected by monetary policy in Brazil.

Note 16. See Lima and Issler (2003) and Marçal and Pereira (2007) for more details on the term structure of the interest rate based on the theory of predictions.

Note 17. In mid-2019, individual investors reached 1 million mark at IBOVESPA, less than $0.5 \%$ of Brazilian population. In the USA, 50\% of Americans invest in equities and stocks. In Europe and Asia, this amount is around $20 \%$ and $30 \%$.

Note 18. The "price puzzle" issue takes place when an increase in the monetary policy instrument (short-term interest rate or SELIC, in Brazil) entails an increase in inflation. The non-occurrence of it reveals sensible specification as for estimated model (Christiano et al., 1999).

Note 19. Different methods of estimation with respect the effects of an interest rate increase on GDP and inflation can be found in Céspedes and Soto (2005), Fernandes and Toro (2005), and Céspedes et al. (2008).

Note 20. For more details on this discussion, see Pimentel et al. (2016) and Tejada and Silva (2008).

Note 21. It should also be noted that exchange rate depreciation leads to an increase in exports of commodities, such as beef, rice, etc., which results in a reduction in the supply of these products internally and an increase of consumer prices.

Note 22. The commodity price variable is represented by the seasonally adjusted Commodity Price Index of the Federal Reserve, Saint Louis. As for a robustness analysis in an autoregressive vector, see Luporini (2008).

\section{Appendix A}

Table A1. Forecast Evaluation-VAR

\begin{tabular}{lccccc}
\hline Variable & Included observations & RMSE & MAE & MAPE & Theil \\
\hline E(Inflation) & 24 & 0.659475 & 0.611262 & 70.90821 & 0.501087 \\
Inflation & 24 & 0.723932 & 0.681968 & 72.08119 & 0.504686 \\
$\ln$ (Exchange Rate) & 24 & 0.144429 & 0.120750 & 7.927278 & 0.051912 \\
$\ln$ (Real Credit) & 24 & 0.147531 & 0.110599 & 2.267598 & 0.014827 \\
$\ln$ (Ibovespa) & 24 & 0.450145 & 0.399607 & 8.192975 & 0.043814 \\
$\ln ($ GDP -1) & 24 & 0.098195 & 0.078718 & 1.247809 & 0.007696 \\
Selic & 24 & 0.666499 & 0.521509 & 41.77970 & 0.418096 \\
\hline
\end{tabular}

Note. Sample range from $01 / 2018$ to $12 / 2019$.

Table A2. Forecast evaluation-BVAR

\begin{tabular}{lccccc}
\hline Variable & Included observations & RMSE & MAE & MAPE & Theil \\
\hline E(Inflation) & 24 & 0.610483 & 0.563112 & 70.15218 & 0.484554 \\
Inflation & 24 & 0.672371 & 0.632453 & 71.33904 & 0.488485 \\
$\ln$ (Exchange Rate) & 24 & 0.107113 & 0.092799 & 6.340141 & 0.039056 \\
$\ln$ (Real Credit) & 24 & 0.142991 & 0.107868 & 2.208626 & 0.014367 \\
$\ln ($ Ibovespa) & 24 & 0.411780 & 0.362181 & 7.362265 & 0.039935 \\
$\ln ($ GDP -1) & 24 & 0.091004 & 0.072807 & 1.152462 & 0.007129 \\
Selic & 24 & 0.621680 & 0.489384 & 40.87576 & 0.400186 \\
\hline
\end{tabular}

Note. Sample range from $01 / 2018$ to $12 / 2019$.

\section{Copyrights}

Copyright for this article is retained by the author(s), with first publication rights granted to the journal.

This is an open-access article distributed under the terms and conditions of the Creative Commons Attribution license (http://creativecommons.org/licenses/by/4.0/). 